\title{
Knowledge Regarding Female Foeticide among Women in a Selected Rural Area at Mangalore with a View to Develop an Information Booklet
}

\author{
Anisha Ann Abraham ${ }^{1}$, Haritha $\mathrm{KH}^{2}$, Tabitha $\mathrm{KK}^{3}$, Tintu Jose ${ }^{4}$, \\ Anupama Tamrakar \\ ${ }^{1-4}$ (B. Sc Nursing IVth Year Students, Yenepoya Nursing College, Yenepoya University, Mangalore, India) \\ ${ }^{5}$ (Lecturer, Department of OBG Nursing, Yenepoya Nursing College, Yenepoya University, Mangalore, India)
}

\section{Introduction}

In the twenty first century with the different advancement in the society, it has been tried to bring women to a stage where they have the equal rights, equal pay and independence but still it is not achieved. Though it may seem that women have a great deal of freedom and independence, the overall condition of women in the world of today is not as it should $b^{1}$. Women have been the subject of deprivation, discrimination, intimidation and injustice treatment in society throughout the history ${ }^{2}$ as the brutal crime like "female foeticide" still exists in the world. They are devalued as human beings from the day they are in the mother's womb. The worst part is that they are even denied the right to be born if their family does not wish them to be borned ${ }^{3}$. This extreme manifestation of violence against women also exists in India ${ }^{4}$. Even though India is advancing at a fast pace in the field of science and technology, but if we look at the root level, gender inequality and female foeticide is still prevalent in the Indian society; in fact, it has been a practiced for hundreds of years ${ }^{2}$.

The causative factors of female foeticide vary according to the countries. In India, the main causes are the deep rooted culture of the son preference, dowry system, deteriorated status of women, foul medical ethics and advancement of technologies ${ }^{5}$. There is the strong cultural belief that son is the way to the heaven, leads to the further generation, take care of them when they become old and always stay with them. People say that "rearing a girl child is watering the neighbor's plant". In India, the age old custom of dowry system puts a restraint on the parents' spirits of a girl child and soon after the birth of a girl; they begin the calculations associated with marriage expenses. We can also see that the inequalities persist in their access to education, health care, physical and financial resources and opportunities in the social, economical, cultural and political sphere. This inequality has reflected in the status of women in the world wide and in India. With the legalization of abortion in India and advancement in the diagnostic techniques to determine the sex of the fetus, illegal sex determination and termination of pregnancies has become an everyday reality ${ }^{5}$. The professionals in the medical field are only too glad to help parents realize their dream of a healthy baby boy ${ }^{6}$.

Even though we cannot see the direct and immediate effect of female foeticide, this has many long term consequences like skewed sex ratio, population decline, female trafficking, increase in rape and assault. When the mothers are undergoing for abortion, there would be fewer births and leads to decline in the country's population. This total wipe-out of one sex is not the way to achieve the target of population control but can lead to worse scenario ${ }^{5}$. Data from the provisional population total census 2011 shows that over $50 \%$ of Karnataka's 30 districts recorded a declined girl child sex ratio in the past decade. In the past 10 years, Karnataka overall sex ratio improved by three points 968 while the girl child sex ratio dropped by three points to 943 . Social crimes like female trafficking, rape, assault and other female harassments have become the common headlines of the news in recent days and it is further increasing day by day ${ }^{7}$. They are usually led to lots of physiological, psychological, economical and social complications to the females ${ }^{6}$.

Keeping this in mind, government of India has tried to stop this crime, introducing the law of Preconception and prenatal Diagnostic Techniques (PCPNDT) Act to prevent sex-selective abortion in $1994^{8}$. Even though there is the law to stop this hilarious crime, non-implementation of the act has been the biggest failing of the campaign. The root cause for the failure is the lack of awareness of this act and law to the public. Hence, this study has been taken up to assess the knowledge regarding female foeticide among women and to develop and distribute the information booklet which further can aid in increasing the awareness about female foeticide and its law among them. 


\section{Methods And Materials}

\subsection{Methods}

A descriptive survey approach was adopted for this study. Hundred married women between the age group of $15-45$ years residing in Kottekar village of Mangalore were selected for samples by using nonprobability sampling technique.

\subsection{Materials}

A structured interview schedule was used as a tool for data collection. The structured interview schedule consisted of section A with demographic proforma of women and section B consisted 22 items on knowledge questionnaire regarding female foeticide and PCPNDT Act.

\subsection{Validity, Reliability of the Tool and Pilot Study}

Content validity of the tool was established with the help of experts form related field. In order to establish the reliability of the tool, it was administered to 10 subjects and calculated using test-retest method following Karl Pearson's formula. The reliability of knowledge questionnaire (r) was 0.98 which indicated that the tool was highly reliable. Pilot study was conducted on 10 samples having the same sample characteristic. The data obtained were analyzed in terms of the objectives by using descriptive and inferential statistics. After conducting the pilot study, it was found that the study was feasible and researchable.

\subsection{Data Collection}

Data was collected from Kottekar village, Mangalore from $22^{\text {nd }}$ April to $2^{\text {nd }}$ May 2014. Prior to the data collection, permission was obtained from the concerned institution and District Health Officer, Mangalore. Informed consent was obtained from the participants. They were also assured for the confidentiality of the information. The total time duration taken for each interview was one hour. After the data collection, the pamphlets with information on female foeticide and PCPNDT Act were distributed to the participants. Data was analyzed using descriptive and inferential statistics. Frequency and percentage were calculated for the demographic characteristics of women and percentage, mean, standard deviation, median, minimum and maximum score was calculated for the knowledge scores. The knowledge scores were arbitrarily categorized into three categories, i.e., poor for 0 - 13 score, average for 14 - 17 score and good for 18 - 22 score. Chi-square test was calculated to see the association between the selected variables and knowledge scores.

\subsection{Demographic Characteristics of Women}

\section{Results}

Hundred women living in Kotekkar village were taken as sample for the study. Less than one fourth of the women (24\%) were in the age group of 31-35 years and 36-40 years and the maximum numbers $(80 \%)$ of women were Muslims. More than one fourth of the women (31\%) had studied in higher secondary and $30 \%$ of women's husband had primary and secondary level of education. Less than half of the women (38\%) were selfemployee and most of the women's (42\%) family income was Rs.5,000 or less. Less than half of the women (37\%) were from extended family and $48 \%$ had one - two numbers of children. Slightly less than two third of the women $(65 \%)$ had female babies. Around half of the women (51\%) had pre-existing knowledge on female feticide and maximum of the women's source of information was mass media (48\%). Slightly more than two third of the women $(77 \%)$ had good relationship with her husband. Majority of them had support from their husbands $(85 \%)$ and their in-laws $(83 \%)$. Detail illustration of demographic characteristics of women is presented in Table 1.

\subsection{Level of Knowledge among women regarding female foeticide and PCPNDT Act}

Findings of the present study disclosed that maximum of the women $(87 \%$ ) had poor knowledge, $12 \%$ had average knowledge and only $1 \%$ had good knowledge on female feticide. The mean knowledge score was $8.78 \pm 3.636$ and the median score was 8 . Analysis of area wise knowledge score depicted that women had highest mean percentage $(43.23 \%$ ), mean score was $5.62 \pm 2.461$ in the area of information on female feticide. Similarly, the mean percentage of knowledge on PNCPDT was 35.11 and mean score was $3.16 \pm 1.802$. The information is displayed in Table 2 and 3.

\subsection{Association between the level of knowledge and selected variables}

Analysis of the association between the level of knowledge regarding female feticide among women and the selected variables demonstrated that there was significant association between the knowledge regarding female feticide and occupation, pre-existing knowledge and source of information $(\mathrm{p}<0.05)$. There was no significant association between the level of knowledge and age, religion, educational, husband's education, 
family income, type of family, number of children, babies' gender, relationship with husband, support from husband and support from in-laws ( $p>0.05)$. The detail result is presented in Table 4.

\section{Discussion}

Female foeticide is curse for the society and it will lead to social degeneration and serious consequences liked skewed sex, decline in population and social crimes like trafficking, rape and assault. Hence creating an awareness regarding consequences of female foeticide and PCPNDT Act among women is very crucial.

Findings of the study depicted that $87 \%$ had poor knowledge, $12 \%$ had average knowledge and only $1 \%$ had good knowledge on female feticide. The mean knowledge score was $8.78 \pm 3.636$. The obtained median score was 8 . This illustrated that women has less knowledge regarding female feticide. This finding is supported by a study conducted by Aishwarya D and Archana SR in which revealed that $55 \%$ of rural women and $70 \%$ of urban women had medium awareness on female feticide ${ }^{9}$.

Analysis of area wise knowledge score divulged that women had highest mean percentage (43.23\%) of knowledge in the area of information on female feticide. The mean knowledge score on information on female feticide was $5.62 \pm 2.461$. Similarly, the mean percentage of knowledge on PNCPDT was 35.11 and mean score was $3.16 \pm 1.802$. A study conducted by Davara KB, Mehta J and Parmar D also revealed that less than half (45.8\%) of women have knowledge about legal punishment for female feticide ${ }^{10}$.

Analysis of the association between the level of knowledge and the selected variables exposed that there was significant association between the knowledge regarding female feticide and occupation, pre-existing knowledge and source of information $(\mathrm{p}<0.05)$. There was no significant association between the level of knowledge and age, religion, educational, husbands education, family income, type of family, number of children, babies' gender, relationship with husband, support from husband and support from in-laws ( $p>0.05)$. Contradictory to this, a study conducted by Yasmin S, Mukherjee A, Manna N, Baur B, Datta M, Sau M, et al reported that there was significant association between the knowledge regarding female feticide and socio economic status, level of education of mother and husband, presence of living children, and husband having preference of sex of the baby $(\mathrm{p}<0.05)^{11}$.

Table 1: Description of Demographic Characteristics of Women

\begin{tabular}{|c|c|c|c|}
\hline Sl.No & Demographic Variables & Frequency & Percentage \\
\hline 1. & $\begin{array}{l}\text { Age in years } \\
\begin{array}{l}\text { a. } 20-25 \text { years } \\
\text { b. } 26-30 \text { years } \\
\text { c. } \quad 31-35 \text { years } \\
\text { d. } \quad 36-40 \text { years } \\
\text { e. } \quad 41-45 \text { years }\end{array}\end{array}$ & $\begin{array}{l}18 \\
17 \\
24 \\
24 \\
17\end{array}$ & $\begin{array}{l}18 \\
17 \\
24 \\
24 \\
17\end{array}$ \\
\hline 2. & $\begin{array}{cl}\text { Religion } & \\
\text { a. } & \text { Hindu } \\
\text { b. } & \text { Christian } \\
\text { c. } & \text { Muslim }\end{array}$ & $\begin{array}{c}16 \\
3 \\
81\end{array}$ & $\begin{array}{c}16 \\
3 \\
81\end{array}$ \\
\hline 3. & $\begin{array}{cl}\text { Educational status of women } \\
\text { a. } & \text { No formal education } \\
\text { b. } & \text { Primary education } \\
\text { c. } & \text { Secondary education } \\
\text { d. } & \text { Higher secondary } \\
\text { e. } & \text { Graduate }\end{array}$ & $\begin{array}{c}14 \\
21 \\
28 \\
31 \\
6\end{array}$ & $\begin{array}{c}14 \\
21 \\
28 \\
31 \\
6\end{array}$ \\
\hline 4. & 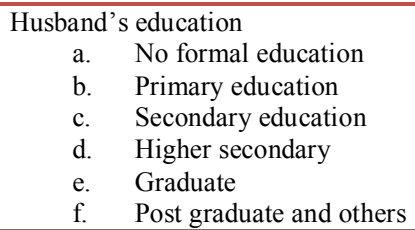 & $\begin{array}{c}9 \\
30 \\
30 \\
27 \\
2 \\
2\end{array}$ & $\begin{array}{c}9 \\
30 \\
30 \\
27 \\
2 \\
2\end{array}$ \\
\hline 5. & $\begin{array}{l}\text { Occupation } \\
\begin{aligned} \text { a. } & \text { Government Employee } \\
\text { b. } & \text { Private Employee } \\
\text { c. } & \text { Self Employee }\end{aligned}\end{array}$ & $\begin{array}{l}21 \\
31 \\
38\end{array}$ & $\begin{array}{l}21 \\
31 \\
38\end{array}$ \\
\hline
\end{tabular}


Knowledge Regarding Female Foeticide among Women in a Selected Rural Area at Mangalore with a

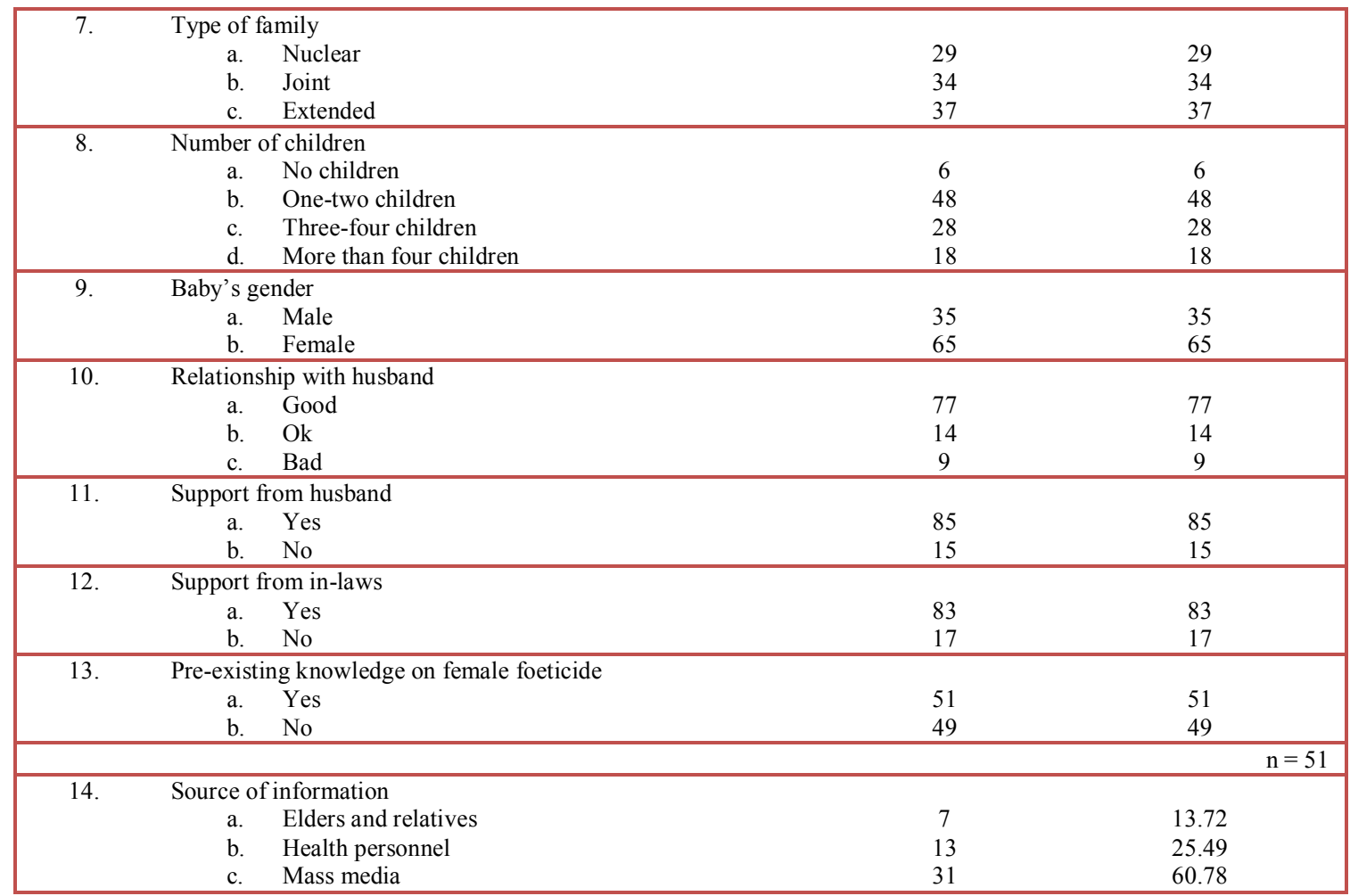

Table 2: Mean, median, maximum and minimum scores and standard deviation of knowledge score of women regarding female foeticide

\begin{tabular}{cccccc} 
& \multicolumn{7}{c}{} & & $\mathrm{n}=100$ \\
\hline \multirow{2}{*}{ Total score } & \multicolumn{9}{c}{ Obtained scores } & Standard deviation (SD) \\
\cline { 2 - 5 } & Maximum & Minimum & Mean (M) & Median & \\
& 2 & 18 & 8.78 & 8 & 3.636 \\
\hline
\end{tabular}

Table 3: Area wise mean, mean percentage, maximum and minimum scores and standard deviation of knowledge score of women regarding female feticide

\begin{tabular}{|c|c|c|c|c|c|c|c|}
\hline \multirow{2}{*}{ Sl. No } & \multirow[b]{2}{*}{ Areas of knowledge } & \multirow[b]{2}{*}{$\begin{array}{l}\text { Total } \\
\text { score }\end{array}$} & \multicolumn{2}{|c|}{ Obtained score } & \multirow[b]{2}{*}{$\begin{array}{l}\text { Mean } \\
\text { score }\end{array}$} & \multirow{2}{*}{ SD } & \multirow{2}{*}{$\begin{array}{c}\text { Mean } \\
\text { Percentage }\end{array}$} \\
\hline & & & Min. score & Max. score & & & \\
\hline 1 & Female foeticide & 13 & 0 & 10 & 5.62 & 2.461 & $43.23 \%$ \\
\hline 2 & PNCPDT & 9 & 0 & 7 & 3.16 & 1.802 & $35.11 \%$ \\
\hline
\end{tabular}

Table 4: Association between the level knowledge of women on female feticide and selected variables

\begin{tabular}{|c|c|c|c|c|}
\hline Sl. No & Variables & Calculated chi -square $(\chi 2)$ & Degrees of freedom (df) & Inference \\
\hline 1 & Age & 8.06 & 14 & $\mathrm{P}>0.05(\mathrm{NS})$ \\
\hline 2 & Religion & 43.316 & 28 & $\mathrm{P}>0.05(\mathrm{NS})$ \\
\hline 3 & Educational & 59.990 & 56 & $\mathrm{P}>0.05(\mathrm{NS})$ \\
\hline 4 & Husbands' education & 66.399 & 70 & $\mathrm{P}>0.05(\mathrm{NS})$ \\
\hline 5 & Occupation & 48.367 & 28 & $\mathrm{P}<0.05(\mathrm{~S})$ \\
\hline 6 & Family income & 55.544 & 42 & $\mathrm{P}>0.05(\mathrm{NS})$ \\
\hline 7 & Type of family & 25.646 & 28 & $\mathrm{P}>0.05(\mathrm{NS})$ \\
\hline 8 & Number of children & 51.547 & 42 & $\mathrm{P}>0.05(\mathrm{NS})$ \\
\hline 9 & Babies gender & 21.689 & 28 & $\mathrm{P}>0.05(\mathrm{NS})$ \\
\hline 10 & Pre-existing knowledge & 42.484 & 28 & $\mathrm{P}<0.05(\mathrm{~S})$ \\
\hline 11 & Source of information & 40.573 & 28 & $\mathrm{P}<0.05(\mathrm{~S})$ \\
\hline 12 & Relationship with husband & 38.175 & 28 & $\mathrm{P}>0.05(\mathrm{NS})$ \\
\hline 13 & Support from husband & 19.599 & 14 & $\mathrm{P}>0.05(\mathrm{NS})$ \\
\hline 14 & Support from in laws & 21.274 & 14 & $\mathrm{P}>0.05(\mathrm{NS})$ \\
\hline
\end{tabular}

Key: NS = Not significant, $\mathrm{S}=$ Significant 


\section{Conclusion}

The findings of the study illustrated that nominal number of women are having good knowledge on female foeticide and PCPNDT Act which indicates that there is still lack of adequate knowledge. Thus, health education programs are required to enhance the knowledge regarding female foeticide and PCPNDT Act to create awareness among women and to reduce female foeticide. The best place to impart the education on to women is rural community. Nursing students, peer groups can be mobilized to conduct these educational programs. Governmental and non-governmental organization should also take initiation to create awareness in public and motivate to reduce this brutal crime. Government should also make strict laws and regulation for prenatal sex determination and female foeticide and punish them who violate these laws. In addition to this, further researches should be conducted to cover other community areas and different part of the country in terms of knowledge, attitudes and practice of female foeticide.

\section{Acknowledgement}

We owe a great deal of gratitude to management of Yenepoya University and Dr. Asha P Shetty, Principal, Dean and Prof. Shanthakumari, HOD, dept of OBG Nursing, Yenepoya Nursing College for providing permission, valuable suggestions and motivation for this study and publication. We extend our grateful acknowledgment to the DHO, Mangalore for giving us permission to conduct the study. We extend our gratitude to all the participants of the study for their enthusiasm and cooperation. We are grateful to those who have supported and motivated for the study and publication.

[1] Women role in the society: www/ananda seva.org/...

\section{References}

[2] Haj L, Umrah. Female feticide. A crime against generation in Kashmir. 2013 Oct11. Available form: free presskashmir.com/femalefeticide-a crime- against-generation/

[3] Kaura, Shanlcar G. Female foeticide on rise the trabune. 2001 June $23^{\text {rd }}$.

[4] Grewal Ian, J. Kishore. Female foeticide in India. IHN. 2004 May, 12-16.

[5] Chaudhary V. Female foeticide: cause, effects and solution. Department of Community Medicine. 2012 May 30.

[6] Smith ND, Luke N, Graveys MC. Too many girls, too much dowry: son preference and daughter aversion in T amil Nadu. Culture, Health and Sexuality. 10 (7), 2008 Oct.

[7] Mathang S. Female feticides pull down child sex ratio. The New Indian Express. 2011 May 23.

[8] Onkar P, Mitra K. The pre-conception and pre-natal diagnostic techniques (prohibition of sex selection) Act 1994. Indian Journal of Radiology and Imaging. 22(2), 2012 Apr-Jun, 141-143.

[9] Aishwarya D, Archana SR. Awareness of rural and urban women about female feticide. Journal of Indian Research. 10(2), 2010 May, 10-12. Available form: www.seea.Org. In/vol 10-2-2010/22.pdf

[10] Davara KB, Mehta J, Parmar D. Female feticide: awareness and perceptions of married women. Journal of Science and Public Health. 3(7), 2014 APR 27, 643-778.

[11] Yasmin S, Mukherjee A, Manna N, Banur B, Datta M, Sanu M, et al. Gender preference and awareness regarding sex determination among antenatal mothers. Scandinavian Journal of Public Health. 41(4), 2013 Jun, 344-50. 